\title{
EXTENSIVE VISCERAL ENDARTERITIS OBLITERANS IN A YOUNG CHILD.
}

\author{
BY
}

JOHN MCMICHAEL, M.B., (From the Paddington Green Children's Hospital, London.)

The following case seems worthy of record on account of the baffling clinical picture and the unique post-mortem findings. The illness occurred in a child of eighteen months, the main clinical features being general malaise and fretfulness, fever and some gastro-intestinal disturbance. Death was caused by thrombosis of the superior mesenteric artery. At autopsy a generalized visceral endarteritis was found with infarcts in various organs.

Bernard H., aged eighteen months, was admitted to the Children's Hospital, Paddington Green on September 7th, 1928.

Alout the first week of August, 1928, he had developed a scarlatiniform rash which disappeared in two days. He had vomited once at the onset but there was no sore throat and he had not appeared ill. The condition was probably a toxic erythema and not scarlet fever.

He remained fairly well until September 2 nd, when he lost his appetite, became listless and seemed to have no energy. Motions became slimy but there was no actual diarrhoea. On the evening of his admission to hospital he vomited four times, the vomit being greenish and watery with mucus. There was a history of slight cough for some weeks.

Previous health and family history. - The child had been previously healthy and there was no history of any preceding infectious or other diseases.

The father and mother, both aged thirty, were well. The Wassermann reaction (taken later) was negative in both. Their first child, a girl, had died of tuberculous meningitis when four years old. The second child was premature and died when a few days old. Present case was the third child. The family was not Jewish. Home conditions were good, the family living in moderately comfortable circumstances in the country.

On admission.-A pale, anæmic, listless child weighing $21 \mathrm{lb} .4 \mathrm{oz}$. Temperature $101.6^{\circ}$; Pulse 110-140 per minute. There was no throat or middle-ear infection. A few slightly enlarged cervical glands were felt. There was slight tenderness in both iliac fossæ but apart from this there were no abnormal physical signs. The lungs were clear. The heart was not enlarged and sounds were closed. The spleen and liver were not enlarged. The urine contained no abnormal constituents and there was no sign of disease in the central nervous system.

During the three days following admission the child was very miserable and unhappy. His temperature fell to normal, but he was passing two or three loose, offensive stools each day. Owing to his fretful state the parents insisted on taking the child home on September 1lth.

At home the temperature was taken daily and it ranged from $98^{\circ}-99^{\circ}$ in the morning to $101^{\circ}-102^{\circ}$ in the evening. Progress was variable. On some days he was quite bright especially in the mornings, but he was always tired in the evenings; on other days he was very listless all day. There was no further diarrhoa, but stools were offensive and dark-coloured, and he continued to vomit about one or twice a week.

On October 3rd, 1928, the child was readmitted to the hospital. Weight was $21 \mathrm{lbs} .2 \mathrm{oz}$. (i.e., practically stationary as compared with weight a month previously). Examination revealed, in addition to the previous findings, that one or two glands were palpable in the right iliac fossa. The von Pirquet test was strongly positive. X-ray examination showed a slight increase of fibrous tissue about the hila of both lungs.

Blood Condition.-Red blood corpuscles 4,580,000 per cmm ., leucocytes 16,000; hæmoglobin 60 per cent., colour index 0.66. Many poikilocytes present. Differential count:- polymorphonuclears 64 per cent., lymphocytes 26.6 per cent., hyalines and transitionals 8.4 per cent., eosinophiles 1 per cent., basophiles not found. 
The stool shewed no occult blood and the bacterial content was normal. The temperature continued to swing from $99^{\circ}$ to $102^{\circ}$.

A clinical diagnosis of glandular tuberculosis was made. On open-air treatment and careful dieting he gained a pound in weight during the next ten days.

On October 16th, he passed a very loose, dark, foul-smelling stool containing mucus and pus-the latter obvious to the naked eye. The temperature rose to $104^{\circ}$ and then slowly settled down in the next twenty-four hours. Palpation of the abdomen and rectal examination revealed nothing. It was surmised that a softened gland might have ruptured into the bowel. Examination of the stool revealed blood and pus. Culturally B.coli and streptococci were found in normal proportions and there was obtained a free growth of a bacillus having the characters of B.dysenteriæ (Sonne). The amount of pus, however, was too abundant for the case to be regarded as one of dysentery only. For the next few days stools were loose and offensive with a little mucus.

At midday on October 26th, he made himself sick by pushing his fingers down his throat. Shortly after this he was found with a little very slightly blood-stained mucus on his pillow, the source of which could not be determined. The child looked pale and anxious : temperature fell from $101^{\circ}$ to $96^{\circ}$ and the pulse rose from 110 to 144 per minute. No physical signs could be elicited in the chest or abdomen. The whole picture was one of shock and no evidence of internal hæmorrhage could be found. He was seen by a surgeon who was not inclined to interfere. At 11 p.m. the abdomen began to become distended but there had been no further vomiting. Between 11 p.m. and 3 a.m. he vomited thrice and death took place at 3 a.m. on October 27th, 1928.

\section{Post-Mortem Report.}

Only an abdominal incision was permitted. On opening the abdomen a little blood-stained fluid escaped and plum coloured coils of small intestine, markedly distended with gas, presented in the wound. These coils consisted of several feet of ileum. The peritoneal surface was smooth and glistening but a few flakes of lymph were occasionally encountered. There was no evidence

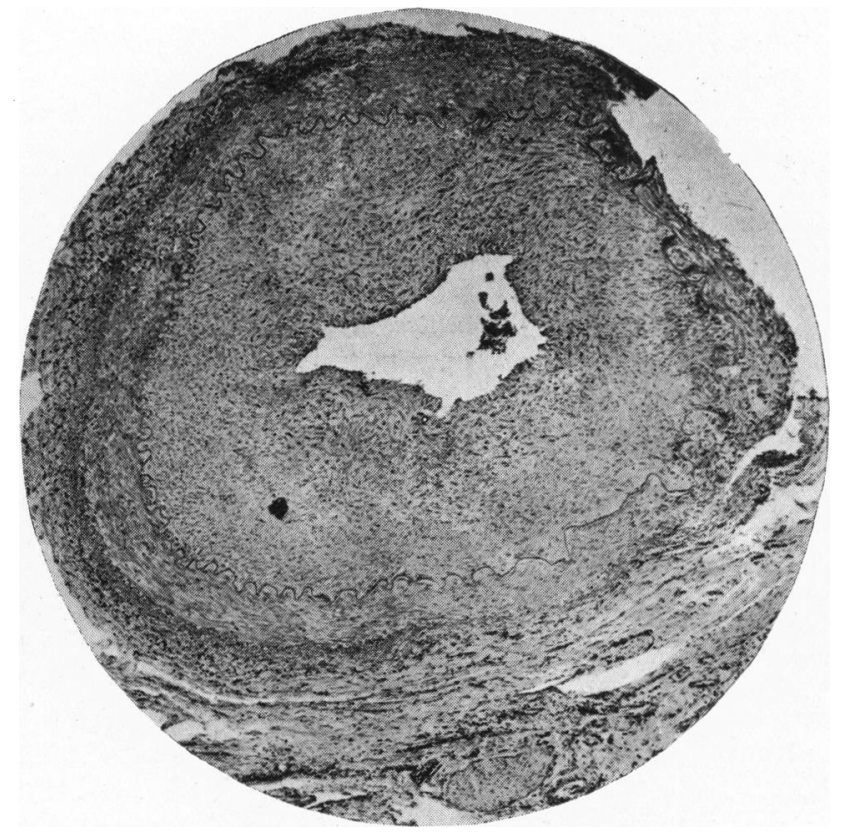

Fig. 1. $\times 75$. Cross section of descending branch of left coronary artery, showing great connective tissue proliferation in the intima. 
of ulceration in either the small or the large bowel. A few enlarged and slightly caseous glands were present in the mesentery near the cæcum.

The spleen was small and firm; along its borders were found five infarcts-some recent, others white in colour and older. The liver was normal. In the kidneys many infarcts were present in both-more numerous in the left kidney (5) than in the right (2). As in the spleen, some were recent and others of longer standing.

The heart was not enlarged. The muscle wall was rather flabby. The coronary vessels were very prominent and of opaque white colour-they felt like dense fibrous cords. Their walls were very definitely thickened and the lumen of the artery extremely narrowed. In the wall of the left ventricle was one firm dense white fibrous patch and a few smaller areas of patchy fibrosis were found towards the apex. None of these fibrotic areas involved the endocardium and there was no ante-mortem thrombus formation in the heart. The valves were normal.

In the lungs all lobes presented on the surface small soft hæmorrhagic and plum coloured areas which appeared to be infarctions. In one or two of these the centres were softening but there were no definite abscesses.

The aortic wall was smooth and presented no atheromatous changes. The mouths of the coronary arteries were not involved.

Microscopical examination.-Sections were made from the heart wall, kidney and spleen. The most notable and the primary change in all these organs was endarteritis obliterans of the small arteries. It is worthy of note that although the descending branch of the left coronary artery and other arteries of a similar size were heavily involved, the smaller arterioles were not affected.

The affected vessels shewed great connective tissue proliferation internal to the internal elastic lamina, with great narrowing of the lumen (Fig. 1). In some sections thrombosis was observed. The media and adventitia were quite normal. The vasa vasorum shewed no perivascular leucocytic infiltration. The results of this obliterating and thrombotic process were visible in the organs examined. In the heart wall, loss of muscle tissue and replacement fibrosis were seen (Fig. 2).

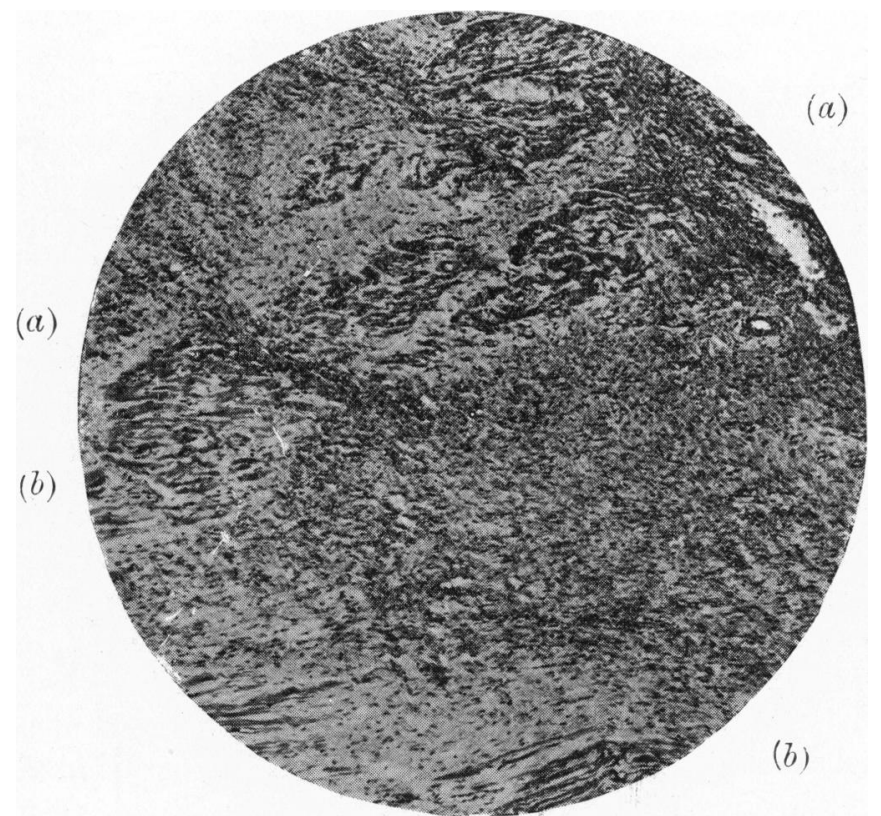

FIG. 2. $\times 100$. Section of the wall of the left ventricle showing loss of muscle fibres (a) and replacement fibrosis (b). 
In the kidney and spleen necrotic areas were present, characterized by loss of structural outlines in the cells and pyknotic nuclei. In the middle of one such area in the kidney an affected vessel was seen containing an organized thrombus.

\section{Discussion.}

The pathological condition described must be termed endarteritis obliterans. Thrombo-angiitis obliterans and polyarteritis nodosa are excluded by the complete absence of any involvement of the adventitia : the herniations of the muscular coat and the aneurysms of the latter condition were completely absent.

On reviewing this case it is realized that the clinical manifestations must, of necessity, be exceedingly protean. Even had the underlying pathological condition been suspected during life it is difficult to see how the diagnosis could have been made, as it is quite impossible to point to any single pathognomonic feature.

It must be assumed that the process of proliferation of the intima had been going on for many weeks before the child's death, and that from the time he came under observation small thrombotic accidents were occurring from time to time right up to the final catastrophe of mesenteric thrombosis which caused his death. The disturbance caused by these events would certainly be sufficient to account for the general malaise and fretfulness which were such prominent features. Had the patient been older, the onset of more or less severe pain might have been determined in various parts of the body where the infarctions took place. The occasional vomiting and the passage of loose stools may have resulted from small infarctions involving the bowel wall. The vomiting also may have been a reflex phenomenon resulting from infarctions in any of the abdominal viscera. The absence of any physical signs is easy to understand, for the infarctions were rever bigger than a pea. Had the urine been examined fully every day some evidence of renal infarction might have been found. A friction rub might also have been heard had a daily examination of the chest been carried out with sufficient zeal. It is worthy of note that there were no attacks of dyspnœa or cyanosis such as are found in the well defined group of cases of pulmonary arteritis in children ${ }^{1}$. It is quite possible that slight hæmoptysis occurred the day before death took place.

The occurrence of fever was a striking phenomenon throughout the illness, and almost certainly was more of the nature of a causal factor than the direct result of the arterial disease.

In considering the ætiology the question of hereditary syphilis arises. Clinically there were no grounds for any suspicion of this disease and it was only after death that the Wassermann reactions were taken in both the father and mother, with a completely negative result. In syphilis and tuberculosis, endarteritis obliterans is common in the neighbourhood of local lesions (e.g., gummata and lung cavities). Generalized visceral endarteritis unassociated with local lesions must be exceedingly rare. In syphilis it occurs in the bloodvesseis of the brain apart from local lesions. In the present case there was no clinical evidence of any involvement of the cerebral arteries, but owing to the limited post-mortem this was not confirmed. Fremont Smith ${ }^{2}$ in a critical 
review of arteriosclerosis in the young states that 'the role of congenital syphilis has been overestimated in youthful cases by earlier writers who were not aware of the part that acute infections play.' He demonstrates that in most of the recorded cases evidence of syphilis was wanting.

Evidence of tuberculous infection was present in the case under discussion in the form of a positive Pirquet reaction and slightly enlarged caseous glands. The possibility that this was an ætiological factor cannot be overlooked but this theory seems untenable for two reasons. First, the frequent incidence of tuberculosis stands in marked contrast with the extreme rarity of the arterial disease under discussion. Secondly, when the arteries are attacked in general tuberculosis the lesion is a definite tuberculous arteritis and totally different from the present arterial disease. One further point is that the child did not belong to the Jewish race, which seems, for some unknown reason, more prone to arterial disease in early life.

The condition must therefore be regarded as a visceral endarteritis due to an acute or subacute infective process of an unknown nature.

In conclusion I have to express my gratitude to Dr. F. Parkes Weber for his kindly interest and to Dr. Reginald Miller for permission to publish the case.

\section{REFERENCES.}

1. Dumas, L. R., Rev. franc de pédiatr., Paris, 1928, IV, 77.

2. Smith, F., Am. J. Med. Sci., Philad., 1908, CXXXV, 199. 